\title{
RECURSOS DE EXPRESSIVIDADE EM AULAS
}

Paulo de Tarso Galembeck (UEL)

ptgal@uel.br

\section{Preliminares}

Em qualquer forma de interação falada (seja nas formas simétricas, seja nas assimétricas), existe a proximidade entre os interlocutores, que, de modo direto ou indireto, interagem na construção do texto. Por isso mesmo, essa forma de realização linguística é caracterizada pela (inter)subjetividade e pela tensão entre os participantes do ato interacional.

Um dos procedimentos que mais de perto assinalam a coparticipação dos interlocutores são os recursos de expressividade. Com esses procedimentos, o falante atribui ênfase ao que diz, com a finalidade de criar um contexto comum e levar os ouvintes a aceitarem seu ponto de vista.

O objetivo deste trabalho é discutir o papel dos recursos de expressividade em aulas, e assinalar o papel deles na exposição dos conteúdos e na obtenção do efeito de sentido desejado pelo professor.

A exposição compõe-se de duas partes. Na primeira, expõemse as noções de subjetividade e tensão conversacional, assim como se discute a noção de expressividade e expõem-se os elementos expressivos. Na segunda seção, discute-se o papel dos elementos expressivos no corpus.

O corpus do trabalho é constituído por gravações de aulas para os ensinos médio e superior. Trata-se dos inquéritos do tipo EF (elocuções formais) $n^{\circ}$ 251, 364, 382 (Projeto NURC/RJ) e 338, 379, 405 (Projeto NURC/SP). 


\section{Fundamentação Teórica}

\subsection{Intersubjetividade e tensão conversacional}

Um dos traços mais marcantes da língua falada são as marcas de subjetividade e intersubjetividade, que, no dizer de Eggins e Slades (1997, p. 49 e ss.), "governam" as diversas formas de interação falada, sejam elas simétricas ou assimétricas. As mesmas autoras assinalam que a tarefa primordial da conversação é a negociação da identidade e das relações, e o componente ideacional (os assuntos tratados) e textual constituem unicamente o pano de fundo para o estabelecimento das relações entre os interactantes.

A noção de interpessoalidade é múltipla, por isso Poyton (1985) e Martin (no prelo), ambos citados por Eggins e Slade (op. cit., p. 52 e ss.) mencionam quatro dimensões desse componente textual:
a) as relações de status, que podem ser previamente definidas ou não;
b) o envolvimento afetivo: expressão de sentimentos (positivos ou ne- gativos) em relação ao interlocutor e assunto tratado;
c) o contato, que diz respeito à familiaridade e a proximidade entre os interlocutores;
d) orientação para a filiação a grupos diversos.

No estudo da expressividade, cabe considerar primordialmente as dimensões do envolvimento afetivo, que coincidem, genericamente, com a tensão coloquial afetiva, conceito estabelecido por Criado de Val. O referido autor (1950, p. 19 e ss.) distingue três tipos de tensão coloquial):

a) tensão coloquial, que atua com um grau mínimo de intensidade, por ser voltada unicamente para o intercâmbio de informações;

b) tensão dialética, que atua sobre os componentes lógicos do diálogo ou os conteúdos ideológicos de cada interlocutor;

c) tensão afetiva, que normalmente coincide e reforça as anteriores, que se origina nas causas emocionais que constituem nota constante e dominante na fala.

Predomina, na fala, o componente intersubjetivo, sobretudo no envolvimento entre os interlocutores e no contato que entre eles se estabelece, e desse fato decorre a tensão coloquial afetiva, de que 
se tratou anteriormente. Disso decorre a relevância, na língua falada, das manifestações de expressividade, assim entendidas as formas de valor emotivo (expressão do eu) e apelativo (envolvimento dos outros).

\subsection{Expressividade e recursos expressivos}

Bally (1967, p. 117) enuncia, de forma sintética, que "será expressivo todo fato de linguagem associado à emoção". Como já foi dito anteriormente, os fatos relativos à expressividade tem valor emotivo ou apelativo e essas funções, de acordo com Mattoso Câmara (1972, p. 136), "têm em comum não serem de fundo intelectivo, mas emocional". Ainda a esse respeito, cabe mencionar as reflexões de Monteiro (1987, p. 22) a respeito de emotividade e expressividade: "a característica fundamental da expressividade reside na ênfase, na força de persuadir ou transmitir os conteúdos desejados, na capacidade apelativa, no poder de evocar elementos evocativos ou conotações".

Do exposto, decorre a dupla direção da expressividade e dos elementos que a manifestam: eles decorrem do caráter intersubjetivo da língua falada e da tensão que se estabelece entre os interlocutores, mas também estão intrinsecamente ligados à função representativa, ao intercâmbio de mensagens com fins de comunicação. Dada essa bifacialidade, os recursos expressivos tendem a ser padronizados e, assim, são tacitamente aceitos pelos interlocutores. Apesar isso, cabe lembrar Sapir (1969, p. 63 e ss.), segundo o qual, de modo genérico, a expressividade manifesta-se com base em padrões socializados, mas também pode manifestar-se de modo individual.

Neste trabalho, adota-se por princípio que a emoção difere em sua intensidade, pois há uma qualidade de emoção em cada enunciação. Por isso mesmo, fica difícil separar os recursos socializados dos recursos padronizados, de modo que essa distinção não será levada em conta.

Urbano (1997, p. 121) afirma que, em tese, caberia distinguir dois tipos de traços e efeitos expressivos: a) aqueles relacionados à expressão de elementos subjetivos e afetivos e ligados, portanto, à subjetividade ou à pessoa do falante; b) os que se vinculam à inter- 
subjetividade, voltados para a interação entre os interlocutores. O problema (e agora já não são palavras do citado autor) é a dificuldade em separar, na dinâmica do texto falado, aquilo que está centrado no autor e aquilo que se refere ao relacionamento entre os interlocutores, pois, em qualquer forma de interação, o sujeito só se define como tal em face do outro. Além disso, pode-se verificar que, de forma geral, os recursos expressivos não só exprimem a emoção do falante/escritor, como também visam a despertar o mesmo efeito no ouvinte/leitor.

Urbano (op. cit., p. 122) apresenta o seguinte quadro dos recursos expressivos:

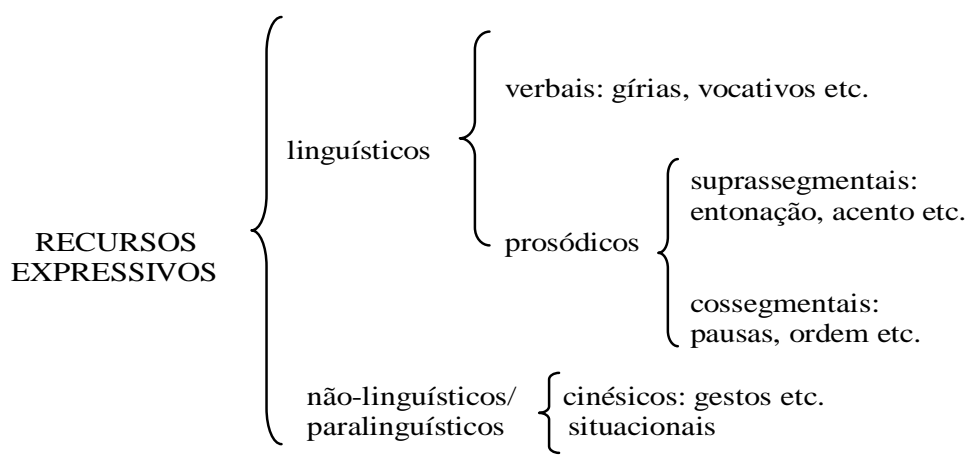

Não é objetivo deste trabalho, efetuar o levantamento e a classificação desses elementos, pois isso foge à proposta deste texto. $\mathrm{O}$ que se busca é verificar a presença deles em interações simétricas (aulas) e discutir-lhes o papel nessa modalidade de interação. Acrescente-se, ainda, que não se tratará dos elementos paralinguísticos (ou cinésicos), uma vez que as gravações do Projeto NURC foram realizadas apenas em áudio.

Em forma de conclusão deste tópico, cabe lembrar as ideias de Bally (op. cit., p. 142), para quem os recursos expressivos são, a um só tempo, intelectuais e lógicos:

intelectuais porque operam com as categorias lógicas em que o espírito classifica as ideias e lógicas porque o peculiar do signo expressivo é tro- 
car as categorias, de modo que exatamente aquela [categoria] que a lógica exige encontra-se disfarçada ou anulada, em prol de outra categoria, com a qual está em conflito.

Essa observação não é impertinente, porém cabe considerá-la de forma bastante relativa, pois a expressividade flui do componente interpessoal e, em aulas, busca chamar a atenção para o que está sendo exposto e envolver os alunos. Os recursos expressivos não se contrapõem às ideias e conteúdos expostos, mas buscam enfatizar a relevância da matéria e encaminhar os ouvintes (no caso, alunos) para as conclusões desejadas. E esse fato evidencia a centralidade do componente interpessoal e as necessidades de elementos que mantenham a tensão entre os interlocutores.

\section{Análise do Corpus}

\subsection{Recursos prosódicos}

Os recursos prosódicos dividem-se em dois grupos: os traços prosódicos suprassegmentais, entre os quais se incluem o tom, o acento, a silabação, os alongamentos, e os traços assegmentais, como as pausas e a ordem. Como assinala Urbano (op. cit., p. 123), trata-se de elementos inerentes à fala, e não se pode pensar num estudo de língua falada que não leve em conta esses elementos.

Entre os traços suprassegmentais, salienta-se, no corpus, o tom, assinalado, sobretudo pela elevação da voz (acento enfático), marca recorrente nos inquéritos analisados. $\mathrm{O}$ acento enfático é empregado com várias funções.

A primeira função a ser apresentada é a indicação clara do assunto que está sendo introduzido ou retomado:

\footnotetext{
(01) Inf.: (...) eu comecei aqui... REVOLUÇÃO FRANCESA... e dando a REVOLUÇÃO FRANCESA... eu indiquei a vocês uma bibliografia... BÁSICA... a bibliografia BÁSICA... sobre revolução francesa $(\ldots)$

(NURC/RJ, 382, 1.02 a 05)

(02) Inf:: (...) vimos aqui... as CAUSAS da Revolução FRANCESA... naturalmente... sabemos que a Revolução Francesa (é muito) grande (...)

(NURC/RJ, 382, 1. 32 a 34)
} 
Nos dois exemplos anteriores, o "mestre" eleva a voz para apresentar aos alunos o assunto que já fora discutido numa aula anterior (a Revolução Francesa e suas causas). Nesse caso, percebe-se que a ênfase é necessária como forma de reavivar a memória dos alunos e, assim, introduzi-los não só no assunto, mas igualmente no contexto comum partilhado que está sendo criado.

A mesma preocupação em enfatizar os conceitos é verificada no exemplo a seguir, no qual o professor opõe as figuras do proprietário e do administrador:

(03) Inf.: (...) nós ativemos a oportunidade de verificar... que há uma distinção hoje... bastante acentuada... entre a figura do PROPRIETÁRIO e a figura... hã... GERENCIAL... não significa que o proprietário não POSSA administrar a sua empresa... mas ele deve administrá-la de acordo com TÉCNICAS GERENCIAIS (...)

(NURC/RJ, 364, 1. 08-13)

Ao opor as figuras do gerente e do administrador, o informante não só reapresenta um assunto tratado numa aula anterior, mas também opõe dois conceitos que constituem a base de sua exposição e encaminha os alunos para as conclusões desejadas.

Observa-se essa mesma oposição num trecho em que o professor expande o tópico da aula:

(04) Inf.: (...) é lógico que numa EMPRESA RUDIMENTAR... o tipo de TAREFA... o tipo de função desempenhada... será bem diferente do que numa EMPRESA MULTINACIONAL... (...) ela vai exigir uma visão muito mais AMPLA... muito mais TÉCNICA... de muito mais CONTEÚDO (...)

(NURC/RJ, 364, 1. 79-85)

A ênfase cumpre o papel de opor dois conceitos ou pontos de vista: a empresa rudimentar, que pode ser gerida de forma empírica, e a empresa multinacional, que necessita de técnicas específicas de gestão. Essa oposição enfática conduz os ouvintes a oporem suas técnicas de gestão e convence-los a aceitarem as técnicas modernas.

A acentuação enfática tem valor apelativo, pois busca criar efeitos de sentido nos alunos, de modo que eles venham a aceitar o ponto de vista do professor. Este busca o envolvimento dos alunos, 
como forma de assegurar-se de que eles estão compreendendo o que está sendo exposto. É o que ocorre no exemplo a seguir, no qual é significativo o emprego da primeira pessoa do plural.

(05) Inf.: (...) imagine... se eu tenho $\mathrm{CaCl}_{2}$ que... no caso... seria $\mathrm{Ca}$... mais dois... mais duas de $\mathrm{Cl}$ ( )... uma rápida análise... para essa... esta equação... essa expressão... NOS LEVA A PERCEBER O SEGUINTE... que... EU VOU TER XIS IONS do tipo A... tá?

(NURC/RJ, 251, 1. 77-81)

Nos exemplos a seguir, os informantes enfatizam um dado termo, como forma de indicar claramente o assunto em pauta, num dado momento da aula.

(06) Inf.: (...) então a demanda de moeda é uma proporção k... a demanda de moeda por TRANSAÇÕES... é uma proporção $\mathrm{k}$ do nível de renda... é a principal razão pelos quais... todos nós agora temos um certo montante de dinheiro no bolso... certo? (...)

(NURC/SP, 338, 1. 230-234)

(07) Inf.: (...) eu estou dizendo que ( ) duas moles por litro... significa... uma ( ) em que um tipo especial chamado MOLARIDADE... mas não é só ESSE tipo de concentração que existe... existe a normalidade... que é um outro tipo de concentração que ao invés de exprimir... a concentração em MOLES... exprime em equivalente.

(NURC/RJ, 251, 1. 44-49)

Ao enfatizar os termos transações, molaridade, moles, os docentes indicam claramente o tópico (ou assunto) de que estão tratando e ressaltam a importância desses conceitos. Esse procedimento mostra que a exposição não é neutra, representa a atuação deliberada do professor sobre os alunos.

Há um direcionamento argumentativo, e ele se verifica também nos casos em que o informante enfatiza uma ou duas sílabas.

(08) Inf.: (...) os testes tem como objetivo... verificar a situação REal:: do indivíduo... eu quero saber REalmente do que esse indivíduo é capaz... então o tes::te já pressupõe:.... que ele tem uma medida objetiva... né? (...)

(NURC/SP, 377, 1. 25-29) 
A ênfase numa sílaba (no caso, uma sílaba átona) busca o mesmo efeito da acentuação da palavra interior: enfatizar aquilo que o "mestre" a deseja ressaltar; ou seja, que aos testes cabe representar precisamente a capacidade do indivíduo.

O mesmo efeito é obtido quando a acentuação enfática recai sobre a sílaba tônica.

(09) Inf:: (...) então no modelo funcionalista o desenvolvimento É:... contínuo... é:.... feito em CRIses... em SALtos... (entende?) (...)

(NURC/SP , 377, 1. 358-361)

A silabação também é realizada com valor enfático, mas tratase um fenômeno de baixa representatividade no corpus:

(10) Inf.: (...) naquele primeiro texto que nós vimos a respeito do estilo... há::.... havia... três ou quatro citações que faziam referência exatamente a isso que estilo mudava... com... a mudança... de vida... e que o estilo e que a arte SEMpre vão refletir uma determinada ma-NEI-ra... de considerar o mundo e a natureza (...)

(NURC/SP, 405, 1. 103-109)

Ao silabar a palavra maneira e proferir enfaticamente a sílaba tônica, o informante coloca em relevo a relação entre o modo de vida de uma comunidade e a arte.

No exemplo a seguir, a silabação é utilizada para realçar a oposição entre dois conceitos que a professora deseja diferenciar de modo explícito.

(11) Inf.: (...) então são dois fatos diferentes... a fi-na-li-da-de (para o que) ela foi feita... e a ca-pa-ci-da-de artística de quem a fez... certo? (...)

(NURC/SP, 405, 1. 279-281)

No exemplo a seguir, a silabação está associada à entoação enfática.

(12) Inf.: (...) a gente vai juntar... demanda e oferta de... moeda... certo? e vai estabelecer o equilíbrio... do mercado.. monetário... demandar de moedas por PRE-CAU-ÇÃO (...)

(NURC/SP, 338, 1. 245-249) 
A ênfase, no exemplo anterior, tem uma função metadiscursiva, pois, com ela, o informante procura evidenciar o próximo assunto.

Com relação aos traços prosódicos cossegmentais, importa realçar as pausas e os deslocamentos. As primeiras constituem um fenômeno de alta recorrência nos textos falados, e sua presença decorre do fato de o texto ser planejado localmente, no momento de sua execução. Entre as pausas, importa considerar, sobretudo, aquelas que se associam à reiteração de ideias ou conceitos.

(13) Inf.: (...) essa guarda essa retenção de... moeda vai ter um custo para ele... o fato dele não estar aplicando... esse dinheiro não estar comprando uma ação hoje... estar retendo a moeda... deixando a moeda ociosa... vai lhe custar alguma coisa (...)

(NURC/SP, 338, 1. 399-404)

As pausas associam-se às estruturas paralelas que reiteram a ideia que o professor está a conceituar, qual seja, o custo da retenção de moeda. Essa associação tem um valor argumentativo, pois reforça o ponto de vista do professor, que busca levar os alunos à aceitação das ideias expostas.

O mesmo valor de reforço e ênfase é verificado nos casos em que as estruturas paralelas têm a finalidade de explicitar um dado conceito.

(14) Inf.: (...) então por exemplo, teste de Binet... teste de inteligência de Binet... ele faz tarefas bem fáceis... que uma criança de três anos pode realizar... até as tarefas de adulto... né? (...)

(NURC/SP, 377, 1. 105-108)

Os deslocamentos também possuem valor expressivo, pois, nas sequências tema-rema coloca-se um elemento na posição inicial, com a finalidade de indicar aquilo de que se vai tratar. Opera-se uma hierarquização das unidades discursivas, e isso tem relevância no estabelecimento da coerência discursiva (VILELA e KOCH, 2001, p. 514).

Veja-se o exemplo: 
(15) Inf.: (...) por exemplo numa igreja hoje você tem imagens que representam... uma ideia religiosa uma série de coisas mas que estão lá para serem vistas também... a igreja é clara... no fundo da caverna num isso eles não poderiam ir lá:: orar:: digamos... porque eles não veriam a:: as imagens... certo? (...)

(NURC/SP, 405, 1. 255-260)

As duas expressões assinaladas são colocadas na posição de rema por dois motivos principais. Inicialmente, a professora realçar cada uma delas individualmente, e reforçar as características de uma e outra. Além disso, a colocação na posição de rema permite salientar a oposição entre ambas as expressões, e reforçar o ponto de vista da informante: as pinturas estão no fundo da caverna por uma finalidade ritual.

\subsection{Elementos verbais}

Inicialmente, serão focalizados neste item os casos de repetições e as paráfrases de valor expressivo, qual seja, aquelas que figuram em estruturas paralelas e têm, pois, valor expressivo.

Ramos (1984, p. 27) enumera as seguintes motivações discursivas da repetição: 1 . explicitar o tópico de uma nova sequência e assegurar a coesão das sequências do discurso; 2. enfatizar elementos da sentença; 3. síntese; 4. recolocação em foco de pormenores de uma narrativa. Neste trabalho, tratar-se-á das repetições do segundo grupo, aquelas que enfatizam elementos da sentença e - como já se viu - figuram em estruturas paralelas.

(16) Inf.: (...) nós vimos que existem dois tipos de oferta de moeda... dois agentes que oferecem moeda... dois agentes que criam moeda... são... é o banco comercial isto é os bancos comerciais... e o Banco Central... o Banco Central de uma forma mais direta... e os bancos comerciais através do mecanismo de multiplicação (...)

(NURC/SP, 338, 1. 1-7).

A repetição dos termos (oferta/oferecem, dois agentes, moeda, bancos comerciais, Banco Central) em estruturas paralelas retoma o que foi dito na aula anterior e reforça os conceitos que devem ser colocados em foco. Trata-se, portanto, de um procedimento que 
tem papel contextualizador, e enfatiza os conteúdos já expostos, com a finalidade de formar um ponto de partida seguro para a exposição que se inicia. É importante, também, lembrar o papel das pausas, que tem um papel expressivo.

As paráfrases cumprem o mesmo papel de reforço, quando figuram em estruturas paralelas.

(17) Inf.: (...) no momento em que essa burguesia sobe ascende ao poder... ela vai destruir... ela vai aniquilar... ela vai apagar... aquelas reminiscências feudais (...) toda a Europa sentiu... as cabeças coroadas da Europa toda... os outros monarcas absolutos da Europa sentiram... que tinha soado a sua hora... que uma nova força se levantava (...)

(NURC/RJ, 107, 1. 178-185)

As paráfrases do trecho citado (sobelascender ao poder; vai destruir/ vai aniquilar; vai apagar; as cabeças coroadas/os outros monarcas absolutos) reforçam, de forma decisiva, o fim das monarquias absolutistas e a ascensão da burguesia.

As estruturas paralelas de paráfrases ou repetição possuem alto poder de ênfase e reforço, pois nelas confluem elementos sintáticos (as estruturas frasais), léxicos (os termos repetidos ou sinônimos) e prosódicos (as aulas). Essa convergência a elas confere um grande valor expressivo, que se soma à função contextualizadora.

Entre os elementos lexicais, cabe lembrar os termos populares (presentes no Inquérito 251), empregados para assegurar um clima de proximidade entre o professor de Química e os estudantes do curso secundário.

(18) Inf.: (...) esse cloro não pode ter vindo de um cloreto de prata (...) de um $\mathrm{HCl}$... de um banana $\mathrm{Cl}$... de um troço qualquer que tenha $\mathrm{Cl}(\ldots)$

(NURC/RJ, 251, 1. 508-512)

\section{Comentários conclusivos}

O exame das ocorrências de recursos de expressividade revela que eles se associam aos conteúdos ministrados e, assim, são essenciais para ressaltar a importância dos assuntos tratados, criar e ex- 
pandir o contexto partilhado pelos interlocutores e encaminhar os alunos às conclusões desejadas. Dada essa pluralidade de funções, fica difícil separar os elementos expressivos (voltados para o falante) dos apelativos (voltados para o ouvinte), pois o uso desses procedimentos constitui uma ação deliberada do professor, diretamente voltada para os alunos.

Reitere-se, enfim, que os recursos de expressividade constituem manifestações essenciais à interação falada e intrínsecas a ela, cria-se, já que, no curso do processo interativo, cria-se um espaço comum partilhado pelos interlocutores e aprofunda-se o envolvimento entre eles.

\section{REFERÊNCIAS}

BALLY, Charles. Traité de stylistique française. 3. ed. Paris: Klincksicck, 1967.

CRIADO DE VAL, Manuel. Estructura general del colóquio. Madrid: Sociedad General Española de Librería, 1980.

EGGINS, Suzanne e SLADE, Diana. Analyzing casual conversation. London, Washington: CASSEL, 1997.

MATTOSO CÂMARA, Jr., Joaquim. Contribuição à estilística portuguesa. 3. ed. Rio de Janeiro: Ao Livro Técnico, 1977.

MONTEIRO, José Lemos. Fundamentos da estilística. Fortaleza: Secretaria de Cultura e Desporto, 1997.

RAMOS, Jânia. Hipóteses para uma taxonomia das repetições de estilo falado. Dissertação de mestrado apresentada à UFMG. Belo Horizonte: s.c.p., 1984

URBANO, Hudinilson. A expressividade na língua falada de pessoas cultas. In: PRETI, D. (Org.). O discurso oral culto. São Paulo: Humanitas, 1997, p. 115-139.

VILELA, Mário e KOCH, Ingedore Villaça. Gramática da língua portuguesa. Coimbra: Almedina, 2001. 